\title{
MUSEOLOGIA E BIOLOGIA: INTERLOCUÇÕES DISCIPLINARES
}

\author{
Josiane Kunzler ${ }^{1 *}$ \\ Manuelina Maria Duarte Cândido ${ }^{2 * *}$ \\ Cristina Paragó Musmann ${ }^{3 * * *}$
}

\section{RESUMEM:}

Discutimos no presente texto aspectos da interdisciplinaridade entre Museologia e Biologia, tomando por base as coleções e museus de Zoologia. Desta forma, a partir de um recorte dentro das coleções de ciências naturais, problematizamos as aproximações entre Museologia e Biologia, discutindo alguns pontos recorrentes na bibliografia e debatendo os diferentes papéis na pesquisa e no processo curatorial. Ao final, trazemos a discussão sobre os desafios e avanços no campo da mediação entre museus e público por meio da ação educativa como mais uma interlocução entre a Museologia e a Biologia.

\section{PALABRAS-CLAVES:}

Projetos interdisciplinares. Museus. Coleções de história natural. Patrimônio cultural. Curadoria.

\begin{abstract}
:
In this paper we discuss aspects of interdisciplinary Museology and Biology, based on Zoology's collections and museums. Thus, from a clipping within natural science collections, we question the similarities between Museology and Biology and discuss about some recurring points in the literature and the different roles in research and curatorial process. At the end, we bring the discussion on the challenges and advances in the field of mediation between museums and the public through educational activities.
\end{abstract}

\section{KEY-WORDS:}

Interdisciplinary projects. Museums. Natural history collections. Cultural heritage. Curator.

\footnotetext{
I * Bióloga, Mestre em Ciências (Geologia), Professora e Coordenadora do Curso de Ciências Biológicas da Faculdade Araguaia.

2 ** Doutora em Museologia, Professora de Museologia da Faculdade de Ciências Sociais da UFG

$3^{* * * *}$ Bióloga, Mestre em Ciências Biológicas (Zoologia), Chefe da Divisão de Fiscalização em Saúde Ambiental da Vigiágua - SMS/Goiânia
} 


\section{Caminhos entre a Museologia e a Biologia}

Entendemos por interdisciplinaridade a combinação em um mesmo projeto de várias inteligências e aportes disciplinares. Isto não corresponde somente ao trânsito de um mesmo indivíduo por várias disciplinas, ainda que isto seja muito comum e extremamente rico no campo do patrimônio cultural. A proximidade de diversas áreas que confluem o estudo patrimonial produz um terreno propício para que a paixão por outros campos seduza os pesquisadores e os faça construir uma trajetória singular, coerente nos objetos, mas múltipla em abordagens. Essa interdisciplinaridade corresponde ao hibridismo das ciências e, por que não, dos cientistas, que é objeto de defesa veemente por intelectuais como Canclini (2000, p. 19): "Precisamos de ciências sociais nômades, capazes de circular pelas escadas que ligam esses pavimentos. Ou melhor, que redesenhem esses planos e comuniquem os níveis horizontalmente".

Neste sentido de ciências nômades, de trânsito entre conhecimentos de diversas origens para solucionar problemas de pesquisa, a metodologia da Museologia tem se destacado com seu grande potencial para interlocução com outras áreas. Projetos e atuação no campo da Museologia destacam-se pela natureza sempre propícia, ou melhor ainda, indissociável da performance interdisciplinar. Este texto, por exemplo, é um exercício interdisciplinar envolvendo três profissionais de áreas diferentes: Museologia e Biologia, e que busca não somente o trânsito dessas profissionais por áreas diferentes, mas apresentar o entrelace natural dessas áreas.

O profissional de Museologia tem um papel imprescindível nos projetos interdisciplinares voltados para a preservação (compreendida como processo envolvendo salvaguarda e também comunicação, em equilíbrio) do patrimônio cultural, como já afirmado por Cândido (2009, p. I):

Percebemos a Museologia como uma articuladora em equipes interdisciplinares, voltada para a comunicação e gestão da informação gerada em outras áreas do conhecimento. A Museologia tem um forte papel de mediação, entre referência patrimonial e sociedade, entre conhecimento científico e público leigo, e entre os diferentes campos do conhecimento que se articulam no museu.

Enquanto profissionais das mais diversas áreas básicas trazem a contribuição da sua área de origem para que, juntamente com a da Museologia, gerem um conhecimento novo, os desta área estão concentrados no desenvolvimento e aplicação de teorias e métodos para equacionar um problema essencial da Museologia que é a relação entre a sociedade e seu patrimônio. É quando o conhecimento daquelas áreas básicas e os acervos ou referências patrimoniais coletados ou identificados no processo de suas pesquisas científicas são alçados a um novo patamar, daquilo que se deseja que permaneça, que a Museologia encontra seu foco de atuação: o destino das coisas (BRUNO, 2009, p. 14). Isto ocorre em projetos que envolvem Museologia e as mais diferentes áreas, e este texto vai se dedicar a aprofundar como ocorrem as interlocuções disciplinares entre Museologia e Biologia.

\section{Coleções Zoológicas}

Um primeiro exemplo concreto dessa interlocução disciplinar é a formação de coleções zoológicas que está na origem de muitos museus de Ciências, de História Natural, ou especializados em Zoologia, Botânica, etc. A história 
dos museus no Brasil não é diferente e está profundamente marcada por esta associação de origem às ciências naturais, como assegura Lopes (1997).A autora demonstra que a Casa dos Pássaros, de certa forma um entreposto comercial encarregado de preparar aves e outros espécimes para coleções européias, esteve na origem do nosso primeiro museu, o Museu Nacional, criado em 1818 por D. João VI, com sede primeiramente no Campo de San'Anna, no centro da cidade do Rio de Janeiro, e posteriormente na Quinta da Boa Vista. Hoje, esse mesmo Museu abriga coleções não só de Zoologia, mas de Botânica, de Arqueologia, de Etnografia, de Antropologia e de Geologia e Paleontologia.

Segundo Meneses (2010), é nestes museus de História Natural, e não em museus históricos, que a América Latina opta por construir suas identidades nacionais. Se para falar do histórico era preciso partir das origens coloniais, as novas nações recorrem, em um primeiro momento, ao que as diferencia das metrópoles: o biológico.

Uma coleção é utilizada para preservar o material de uma pesquisa realizada. Os espécimes depositados em coleções e utilizados em um estudo poderão ser reavaliados por outros pesquisadores que desejarem corroborar ou refutar um trabalho.A formação de coleções biológicas tem profunda relação com a Taxonomia, parte da Biologia que aborda a classificação dos seres e torna-se a base para os estudos posteriores mais específicos, sejam de Ecologia, Evolução, Fisiologia, Bioquímica ou qualquer outro, já que para se ter a certeza da espécie-objeto, faz-se necessário utilizar as ferramentas da Taxonomia.

Depois de um trabalho é preciso preservar o material utilizado, desta forma, se outros pesquisadores precisarem confrontar com novos espécimes o resultado será mais fidedigno. Então o material deve ser identificado, catalogado e depositado em uma coleção (FERNANDES et al., 2006, p. 4). Um exemplo da importância da preservação de material em coleção é revelado por Kunzler (20I2). Os primeiros fósseis de invertebrados coletados no estado de Mato Grosso foram identificados por Derby (1895) e depositados na coleção de Paleoinvertebrados do Departamento de Geologia e Paleontologia do Museu Nacional. Entre eles estavam os exemplares tipo de uma nova espécie de braquiópodes (conchas marinhas) que, por desconhecimento da comunidade científica, vinha recebendo atribuições errôneas. Passado mais de um século, uma revisão taxonômica da identificação feita por Derby (I895) que viesse solucionar o problema da taxonomia dessas conchas foi possibilitada devido à preservação dos espécimes em coleção.

Denominamos como coleção taxonômica a reunião ordenada de espécimes mortos ou partes corporais desses espécimes, devidamente preservados para estudos. Em Zoologia, para nos circunscrevermos apenas a uma parte da Biologia, de acordo com os estudos realizados, também são incorporados às coleções o que denominamos de "trabalho animal", que podem ser objetos e produtos resultantes de atividades dos animais, tais como abrigos, ninhos, excrementos, rastros, pegadas e outros (PAPAVERO, 1994).

Os espécimes, já mencionados, servirão de parâmetros para elucidarem dúvidas que porventura apareçam durante um estudo. As coleções podem fornecer material para exposições, para uso em salas de aula e também servirem como ferramenta na identificação de outros animais, além de lançar (e atrair) novos olhares sobre políticas públicas, pesquisas médicas, farmacêuticas e agronômicas, entre outros (KURY et al., 2006, p. 21 ).

O que é curioso e positivo é que, ao contrário de outras áreas do conhecimento cujas raízes acadêmicas estiveram entrelaçadas com a formação e o 
estudo de coleções, mas hoje sofrem um processo de distensão nesta relação, a Biologia continua tomando como indispensáveis os processos de colecionamento e curadoria em suas pesquisas e ensino universitário ${ }^{5}$.

De acordo com Papavero (1994) podemos encontrar cinco tipos de coleções, a saber: I) coleções didáticas, que envolvem material destinado a ensino, demonstrações e treinamento; 2) coleções de pesquisa, como as grandes coleções gerais, que podem estar vinculadas a universidades ou museus, e permitem vasto desenvolvimento dos estudos taxonômicos e biológicos, além das coleções particulares, que advém de colecionadores e aficionados que através de recursos próprios reúnem material de grupo ou grupos zoológicos; 3) coleções regionais, que reúnem espécimes de uma localidade específica, representando quase integralmente a fauna em questão; 4) coleções especiais, que podem ser de diversos tipos, como por exemplo, coleções de interesse econômico ou de levantamento faunístico e 5) coleções de identificação, que servem de apoio à rotina de identificação de material zoológico para as mais diversas finalidades, e estão inseridas em instituições ligadas a esta prestação de serviço.

Da convergência de saberes da Biologia e especificamente da Zoologia com a Museologia, podem surgir ambientes apropriados para a representação da diversidade biológica de organismos tanto fósseis como recentes. Um museu de história natural é um lugar que abriga um tesouro para quem necessita consultar seu acervo, e por isso, em quase todos os países do mundo em que as ciências biológicas são consideradas de primeira importância para o desenvolvimento social, uma coleção de história natural ali se encontra (ZAHER;YOUNG, 2003, p. 25). Estas instituições, longe de se prenderem a um modelo de ciência ultrapassado, conectado apenas com suas origens, atualizam-se constantemente, acompanhando os progressos científicos não somente das áreas básicas, mas também da Museologia. Um exemplo disto é o Netherlands Centre for Biodiversity - NCB Naturalis, novíssimo museu holandês resultante de uma fusão de instituições anteriormente existentes: o Zoological Museum Amsterdam (ZMA), o National Museum of Natural History Naturalis e partes do National Herbarium of the Netherlands (NHN). Juntas, as coleções formam o quinto maior acervo do mundo em biodiversidade e foi inaugurado em 28 de janeiro de 2010 (CÂNDIDO, 20I3, p. 31). Além de ser um caso singular de fusão em grande escala de instituições museológicas ${ }^{6}$, o Naturalis está em dia com os conceitos de biodiversidade, popularização da ciência e acessibilidade, entre outros que juntamente com seu refinamento expográfico habilitam-no como importante

4 É a crítica de Bruno a respeito de como áreas das Ciências Humanas têm lidado com esta questão: "Em um primeiro momento, verificamos que o abandono dos cursos de formação profissional, como por exemplo, em Antropologia, Arqueologia, História, Sociologia, entre outros, em relação à importância dos estudos de cultura material e, especialmente, no que tange aos princípios e práticas inerentes ao processo curatorial, tem legado novas gerações descomprometidas e despreparadas para o exercício e consolidação de cadeias operatórias de procedimentos técnicos e científicos relativos à salvaguarda e comunicação das coleções museológicas, fragilizando a atuação das instituições” (BRUNO, 2009, p. 22).

5 Vale esclarecer que não somente a formação de novas coleções é importante neste processo. $O$ excesso de objetos nas reservas técnicas - a obesidade galopante dos museus (BALERDI, 2008) - mostra que muitas vezes o mais relevante seria retomar o estudo de coleções já existentes, questionando procedimentos atualmente em voga na Arqueologia, por exemplo, de um quase completo abandono do patrimônio já preservado por uma busca incessante de novos artefatos em campo.A não retomada de acervos já existentes deve levar a um questionamento sobre para que, então, musealizar novos acervos. Ou se alguma forma de descarte/devolução após a pesquisa não seria mais coerente e sustentável em longo prazo. Esta, entretanto, não é uma discussão prioritária no presente texto (ver BRUNO; ZANETTINI, 2007; CÂNDIDO, 2005;).

6 Há outros exemplos de fusão no mundo dos museus, originando instituições de menor porte, como o das coleções que geraram o atual Museu de Arqueologia e Etnologia da Universidade de São Paulo. Mas os processos de desmembramento são mais comuns. 
marco entre os museus de ciências da contemporaneidade.

Segundo Zaher e Young (2003, p. 25) encontra-se no Brasil o maior acervo do mundo sobre a região neotropical, sendo o Museu Nacional, o Museu Paraense Emílio Goeldi e Museu de Zoologia da USP, os mais ricos em biodiversidade brasileira. São coleções importantes e reconhecidas internacionalmente por sua importância como acervo e por todo o trabalho de pesquisa realizado pelos profissionais com elas envolvidos. No entanto, é diagnosticado, como ponto fraco brasileiro, a carência de curadores devidamente capacitados na gestão de coleções biológicas e também de apoio técnico na manutenção das coleções (KURY et al, 2006, p. 31 ). Estes autores estão trabalhando, portanto, com um conceito específico de curadoria, tomada como o trabalho das áreas básicas sobre os acervos.

\section{A questão da curadoria}

Há, entretanto, outro conceito de curadoria. Isto foi discutido, em publicações como o Caderno de Diretrizes Museológicas 2, no qual Bruno (2008) aponta uma bifurcação na trajetória deste conceito:

[...] é possível constatar que o conceito de curadoria surgiu influenciado pela importância da análise das evidências materiais da natureza e da cultura, mas também pela necessidade de tratá-las no que corresponde à manutenção de sua materialidade, à sua potencialidade enquanto suportes de informação e à exigência de estabelecer critérios de organização e salvaguarda. Em suas raízes mais profundas articulam-se as intenções e os procedimentos de coleta, estudo, organização e preservação, e têm origem as necessidades de especializações, de abordagens pormenorizadas e do tratamento curatorial direcionado a partir da perspectiva de um campo de conhecimento (BRUNO, 2008, p. 19).

A mesma autora ressalta a dissonância entre um tratamento curatorial marcado pelas responsabilidades solidárias - processo curatorial que Cândido (20I3) destaca na figura I como campo da pesquisa aplicada em Museologia - e a onipotência da figura do curador, geralmente um profissional oriundo da área básica, que varia de museu para museu.

\section{PRESERVAÇÄO / MUSEALIZAÇÃO}

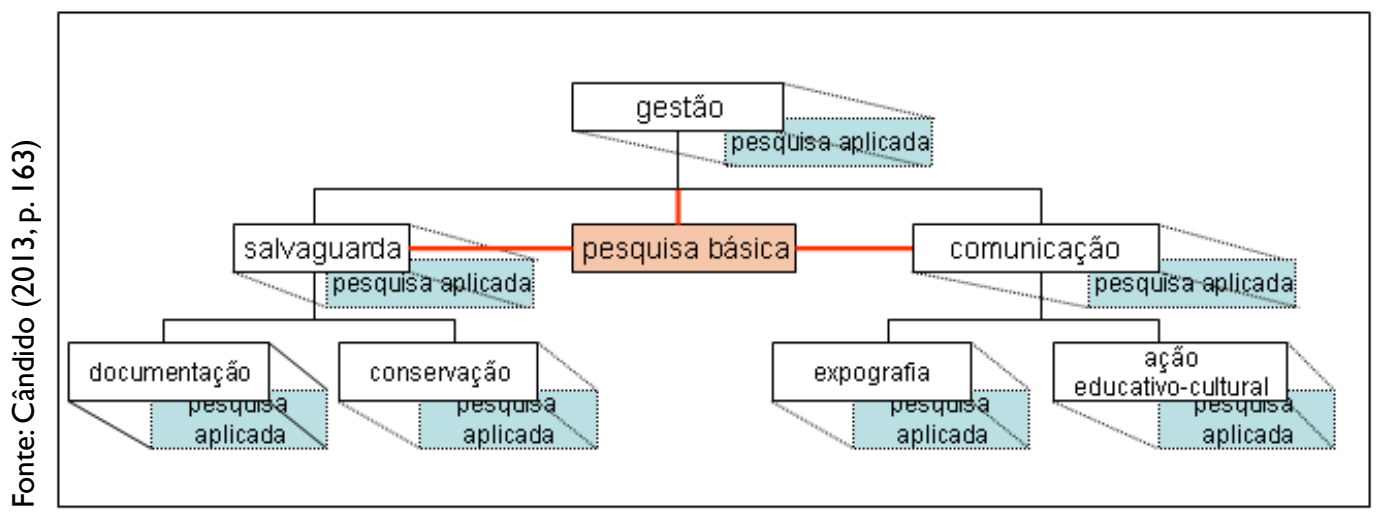

Figura I: Pesquisa básica e pesquisa aplicada nos processos de musealização.

Ao nos alinharmos com estas duas autoras estamos entendendo que há uma curadoria ligada à área básica que consiste em pesquisa e seleção daquilo que tem potencial comunicativo suficiente para justificar sua inclusão na complexa e 
dispendiosa cadeia operatória museológica que envolve salvaguarda e comunicação, mas também um processo curatorial mais amplo.Assim, no museu, o processo curatorial será o conjunto de todas as atividades desenvolvidas a partir do acervo, combinando responsabilidades solidárias de todas as disciplinas envolvidas.

Entretanto, a ausência de profissionais habilitados a atuar de uma maneira mais transversal na curadoria de coleções e no trabalho interdisciplinar, coloca a realidade dos museus brasileiros na contramão da grande biodiversidade que encontramos em nosso território, com uma tendência ao tratamento segmentado das coleções. Professores de graduação e pós-graduação que desenvolvem suas pesquisas, paralelamente cuidam das coleções de seus respectivos grupos de interesse, dividindo seu tempo com preparação de aulas, burocracias administrativas e a curadoria, esta realizada como uma atividade à parte de outras curadorias no mesmo museu.

A própria divisão do espaço tanto de laboratórios como das exposições muitas vezes reflete esta segmentação, com setores separados utilizando, não raro, métodos de trabalho e de descrição distintos, e resultando em exposições que são formadas por salas ou módulos destinados a cada tipologia de acervo, com linguagens visuais nitidamente desalinhadas.

Como os pesquisadores da área básica possuem um conhecimento altamente especializado em taxonomia, mas em geral pouco preparo nos aspectos do planejamento e gestão de uma instituição museológica, escasso conhecimento sobre necessidade específicas de conservação, de comunicação ou de adequação ao público, alguns problemas acabam recorrentes:

- A estrutura física é na maioria das vezes inadequada, às vezes até mesmo sem o devido controle da temperatura, umidade e luminosidade, fazendo com que os tipos sejam mantidos em condições desfavoráveis;

- Questões como acessibilidade podem não ser consideradas;

- As exposições podem não ter o apelo visual e midiático que pode colocar ou não o museu no rol das atrações preferenciais em uma cidade para públicos locais e turistas;

- A quantidade e características dos textos das exposições tendem a se espeIhar em formatos mais adequados à comunicação entre pares que com o público leigo;

- A ação educativa pode ser exclusivamente caracterizada como visita-palestra e desconsiderar o papel provocativo da comunicação em museus e outros formatos mais dialógicos (MARANDINO, 2008, p. 22-23).

- A parca difusão da importância de uma coleção fora dos meios acadêmicos somente torna mais difícil obter apoio dos gestores.

Alguns destes pontos de atenção poderão ser equacionados com a inserção de profissionais da área de Museologia em equipes interdisciplinares e com a difusão do conceito de processo curatorial solidário, partilhado entre pesquisadores das áreas básicas e aplicadas.

O trabalho de curadoria de uma coleção zoológica precisa deixar de ser amador e passar a ser realizado por profissionais não somente ligados à Zoologia, mas também à Museologia, unindo as respectivas áreas do conhecimento e criando condições para que as coleções possam contar com melhor estrutura de guarda, acondicionamento, conservação e gerenciamento da informação, bem como de extroversão digna de seus potenciais. Os pesquisadores das áreas básicas carecem da possibilidade de se dedicar à pesquisa sem necessariamente serem responsáveis por todo o processo curatorial da coleção, que deveria contar com um sistema curatorial integrado com outros perfis de acervo porventura existentes na mesma instituição, gerenciado por profissionais cuja responsabilidade e pesquisas (aplicadas) fossem centradas na curadoria. 
É necessário, finalmente, que se realize um trabalho tanto no campo da formação como na conscientização da importância de coleções taxonômicas. Para isso, foram criadas, em 2006, as diretrizes para uma política dos acervos biológicos no Brasil (KURY et al., 2006).

\section{As coleções zoológicas e a função educativa}

Compreendemos a curadoria de uma forma ampla, como processo curatorial completo que envolve não somente a pesquisa sobre os acervos, a documentação e a conservação dos espécimes (salvaguarda), mas a extroversão das coleções e do conhecimento sobre elas. A comunicação patrimonial, viabilizada pela elaboração e execução de exposições e pela ação educativo-cultural surge, desta feita, como faceta da curadoria em que também interagem, no caso em análise, Museologia e Biologia ${ }^{7}$. Dentro da rotina das ciências e no seu processo de ensino-aprendizagem, a ênfase na importância da interdisciplinaridade tem sido uma constante. Não se pode fazer ciência com pensamento compartimentalizado porque cada conceito oriundo das diversas áreas utilizadas no estudo contribuirá na construção do conhecimento desejado. Esta forma de trabalho também se torna muito valiosa quando pensamos em um museu e toda a sua riqueza de informações e experiências que deve ser explorada de forma adequada, permitindo assim que os usuários e os estudantes que frequentam o museu possam tirar o máximo proveito do patrimônio ali preservado.

A confluência em um projeto museológico ou expositivo dos conhecimentos da Museologia e da Zoologia permite que se possa construir, por exemplo, exposições taxonômica e sistematicamente corretas, capazes de demonstrar a diversidade zoológica, a realidade ecológica e evolutiva, mas também esteticamente e ambientalmente agradáveis, didáticas, socialmente responsáveis e inseridas nas reflexões contemporâneas sobre preservação do patrimônio cultural ${ }^{8}$.

Se o museu também investe em uma ação educativa adequada, a difusão científica terá mais qualidade, como apresentado por Krombaß \& Harms (2008). A área da ação educativo-cultural em museus de ciências é extremamente fecunda em todo o mundo e no Brasil e ganha cada vez mais o interesse de pesquisadores e profissionais da área da educação.

Pelo fato de abordarem conteúdos científicos por meio de exposições interativas, educadores e professores da área de ensino de ciências passaram a ver nessas instituições condições para que funcionassem como um suplemento ao ensino promovido nas escolas. As diversas interações entre os estudantes e os aparatos desse tipo de exposição aumentavam a curiosidade e estimulavam o comportamento investigativo, o que poderia ser a base de idéias e de atividades para a sala de aula. Percebe-se, portanto, que um dos objetivos declarados desses museus de ciência - enfatizar a abordagem participativa ao apresentar idéias e atividades - encontrou grande ressonância nos setores educacionais que começaram a utilizá-los como centros de educação em ciências (GOUVÊA et al., 200I, p. 172).

7 Ou Museologia e outras áreas básicas quando se tratarem de outras tipologias de museus e acervos.

8 Trabalhamos aqui com o conceito antropológico de cultura, que engloba aquilo que é transformado física ou simbolicamente pelo homem e, portanto, compreendemos as paisagens e outros bens chamados 'naturais' como parte de um universo apropriado pela cultura. Neste sentido, mesmo elementos da natureza não deslocados, mas identificados e ressignificados, são cultura. As coleções biológicas e minerais formam, portanto, a faceta mais evidente de uma apropriação cultural que o homem faz sobre a natureza. Como a constituição do que chamamos patrimônio sempre pressupõe recortes atribuições de valor, não podemos, dentro deste escopo, falar de patrimônio natural. 
Chelini e Lopes (2008, p. 206) salientam que as exposições realizadas por essas instituições são ferramentas essenciais no processo de divulgação de saberes e, consequentemente, no processo de ensino, uma vez que atuam diretamente na interface entre o público e o museu. Chagas (1993, p. 54) defende que organizar exposições temporárias, utilizando exibições interativas, dedicadas especialmente à população estudantil, evidencia a tendência atual da maioria dos museus de história natural.

No âmbito da expografia, a parceria Museologia - Biologia na construção de uma exposição baseada na Zoologia é essencial, pois características inerentes os objetos bem como o tipo de estudo que se fez sobre ele deverão ser considerados nas escolhas de partido expográfico e soluções. Esta parceria é ainda mais profunda no que tange à mediação entre o público e a exposição, como destaca Marandino (20I2, p. 29) de um documento francês "Rapport au Ministre d'État Ministre de l'Éducation Nationale - Les Musées de L'Education Nationale: Mission d'étude et de réflexion, 199|":

[...] não podemos deixar o indivíduo sozinho diante de coleções de objetos ou de uma apresentação fria de fatos científicos ou técnicos (versão arcaica de museu). Mas também devemos igualmente dispensar as facilidades preguiçosas e passivas da informática e da caixa preta. Num espírito pedagógico ativo, o museu deve ser apresentado de forma que os homens possam se comunicar com o objeto (objeto técnico ou objetos de experiência) e não apenas se contentarem em contemplá-los. Para isto, o contato interpessoal, com apresentadores, encarregados de exposições, cientistas ou os guardas é o recurso mais seguro. 'O museu deve ser interativo e vivo'. E para que ele 'seja vivo e integrado a uma pedagogia ativa', é necessário 'poder tocar e dialogar' (MARANDINO, 2012, p. 29).

Não obstante, o museu também dispõe de outras ações que podem contribuir para a divulgação do conhecimento biológico. Para Falcão (2009, p. 16), podem ser consideradas ações educativas de efeito as visitas "guiadas", "monitoradas", "orientadas" ou mesmo "dramatizadas" e as exposições itinerantes, o atendimento e preparo dos professores, as oficinas, os cursos e as conferências, as mostras de vídeos e as contações de histórias, além da confecção de materiais como livros, cartilhas e folhetos informativos, kits pedagógicos e jogos.

\section{Considerações finais}

Ao discutirmos a relação Museologia e Biologia temos a oportunidade de contribuir com a construção dos saberes de duas disciplinas que devem trabalhar juntas pela difusão do conhecimento e têm os museus como palco de atuação. Cada uma em suas especificidades, realidades e exigências. No entanto, relacionadas por terem como fonte e destino de objeto de trabalho a sociedade em geral.

Essa relação pode acontecer, como foi visto, na formação de coleções, criação de exposições e museus, ou ir além. A história dos museus e a história da pesquisa científica caminham lado a lado e esta colaboração mútua deve continuar, com abertura para que todos os lados possam se deixar permear pelo conhecimento e experiência dos outros campos, sem limitações baseadas em pequenas vaidades e defesa inflexível dos mesmos. A interlocução ajudará a definir os limites e convergências dos diferentes saberes na prática interdisciplinar, em benefício maior da sociedade, por quem cabe preservar todo este patrimônio. 


\section{Referências}

BALERDI, Ignácio Díaz. La memoria fragmentada: el museo e sus paradojas. Gijón, Asturias: Ediciones Trea, 2008. (Biblioteconomía y Administración Cultural, 183)

BRUNO, Maria Cristina Oliveira. Definição de curadoria: os caminhos do enquadramento, tratamento e extroversão da herança patrimonial. In:JULIÃO, Letícia; BITTENCOURT, José Neves (Org.). Mediação em museus: curadorias, exposições, ação educativa. Belo Horizonte: Secretaria de Estado de Cultura de Minas Gerais/ Superintendência de Museus, 2008. (Caderno de diretrizes museológicas, 2).

BRUNO, Maria Cristina Oliveira. Estudos de cultura material e coleções museológicas: avanços, retrocessos e desafios. In: CULTURA material e patrimônio da ciência e tecnologia. Rio de Janeiro: Museu de Astronomia e Ciências Afins, 2009. (Livro eletrônico).

BRUNO, Maria Cristina Oliveira; ZANETTINI, Paulo. O futuro dos acervos. In: CONGRESSO INTERNACIONAL DE ARQUEOLOGIA DA SAB, I.; CONGRESSO NACIONAL DA SAB, I4., 2007, Florianópolis.Anais... Florianópolis: Habilis, 2007.

CANCLINI, Néstor García. Culturas Híbridas: Estratégias para Entrar e Sair da Modernidade. São Paulo: Edusp, 2000.

Cândido, Manuelina Maria Duarte. Cultura material: interfaces disciplinares da Arqueologia e da Museologia. Cadernos do CEOM, v. I8, n. 2 I, p. 75-90, 2005.

Cândido, Manuelina Maria Duarte. Gestão de museus, um desafio contemporâneo: diagnóstico museológico e planejamento. Porto Alegre: Medianiz, 2013.

Cândido, Manuelina Maria Duarte. Museus e conhecimento interdisciplinar. Revista Museu, v. I, p. I, 2009.

CHAGAS, Isabel. Aprendizagem não formal/formal das ciências: relações entre museus de ciência e escolas. Revista de Educação, v. 3, n. I, p. 5I-59, 1993.

CHELINI, Maria-Julia Estefânia; LOPES, Sônia Godoy Bueno de Carvalho. Exposições em museus de ciências: reflexões e critérios para análise.Anais do Museu Paulista, v. 16, n. 2, p. 205-238, 2008.

DERBY, Orville Adelbert. Nota sobre a geologia e paleontologia de Matto Grosso. Archivos do Museu Nacional, n. 9, p. 59-88, 1895. Disponível em: <www. obrasraras.museunacional.ufrj.br/o/0053/59-88.pdf>.Acesso em: 05 dez. 2013.

FALCÃO, Andréa. Museu como lugar de memória. Museu e Escola: Educação Formal e Não-Formal, v. 19, n. 3, 2009.

FERNANDES,Antonio Carlos Sequeira et al. Os fósseis estrangeiros da coleção de Paleoinvertebrados do Museu Nacional. Publicações Avulsas do Museu Nacional, n. I08, p. I-36, 2006.

GOUVÊA, Guaracira et al. Redes cotidianas de conhecimento e os museus de ciências. Parcerias Estratégicas, n. I I, p. 169-174, 200 I.

KROMBAß, A.; HARMS, U. Acquiring knowledge about biodiversity in a museum: are worksheets effective? Journal of Biological Education, v. 42, n. 4, p. I57-I63, 2008. KUNZLER, Josiane. Resgate histórico e taxonomia dos braquiópodes devonianos do estado de Mato Grosso depositados no Museu Nacional/UFRJ. 2012. Dissertação (Mestrado)-IGeo, Rio de Janeiro, 2012.

KURY,Adriano B. et al. Diretrizes e estratégias para a modernização de coleções biológicas brasileiras e a consolidação de sistemas integrados de informação sobre biodiversidade. Brasília: Centro de Gestão e Estudos Estratégicos: Ministério da Ciência e Tecnologia, 2006. 
LOPES, Maria Margareth. O Brasil descobre a pesquisa científica: os museus e as ciências naturais do século XIX. São Paulo: HUCITEC, 1997.

MARANDINO, Martha (Org.). Educação em museus: a mediação em foco. São Paulo: FEUSP, 2008.

MARANDINO, Martha. O mediador na educação não-formal: algumas reflexões. In: CADERNO MUSEU DAVIDA. O formal e o não-formal na dimensão educativa do museu. Rio de Janeiro, 2012.

MENESES, Ulpiano T. Bezerra de. O Museu e a questão do conhecimento. In: GUIMARÃES, Manoel Luiz Salgado; RAMOS, Régis Lopes (Org.). Futuro do pretérito: escrita da história e história do museu. Fortaleza: Instituto Frei Tito de Alencar, 2010.

PAPAVERO, N. Fundamentos práticos de taxonomia zoológica. 2. ed. São Paulo: UNESP, 1994.

ZAHER, Hussam;YOUNG, Paulo S.As coleções zoológicas brasileiras: panorama e desafios. Ciência e Cultura, v. 55, n. 3, p. 24-26, 2003. 